\title{
A IRRETROATIVIDADE DO NOVO CÓDIGO FLORESTAL E A JURISPRUDÊNCIA DO SUPREMO TRIBUNAL FEDERAL
}

\author{
Edson Damas da Silveira \\ Procurador de Justiça em Roraima, especialista, mestre e doutor em direito, professor da \\ Especialização em Direito Socioambiental da PUC/Pr. e do Mestrado em \\ Direito Ambiental da UEA. \\ Email: e.damas.silveira@uol.com.br
}

Serguei Aily Franco de Camargo

Possui graduação em Direito (UNESP), Mestrado em Conservação e Manejo de Recursos Naturais (CEA-UNESP), Doutorado em Aquicultura em Águas Continentais (CAUNESP), Pós-Doutorado em Ecologia (NEPAM-UNICAMP), Pós-Doutorado em Direito Ambiental (IB-UNESP) e Pós-Doutorado em Agroecologia (UERR). Professor e pesquisador da Universidade Estadual de Roraima, Assessor Jurídico de Procurador de Justiça (MPERR) e professor dos cursos de Direito do Centro Universitário Estácio da Amazônia e das Faculdades Cathedral de Boa Vista. Email: sergueiaily@mprr.mp.br

\begin{abstract}
RESUMO
Este artigo apresenta reflexões acerca da constitucionalidade de dispositivos do Novo Código Florestal, a partir de julgamento realizado pelo Supremo Tribunal Federal, em fevereiro de 2018. Discute-se a eventual anistia a agentes degradadores do meio ambiente, por força de uma interpretação do referido diploma legal. Assim, a partir da análise do discurso dos votos dos Ministros da Suprema Corte, busca-se subsidiar tese conciliadora a permitir o entendimento de que a vedação ao retrocesso em matéria ambiental não limita o legislador. No mesmo sentido, a ponderação entre a retroatividade mais benéfica da lei e a necessidade da reparação dos danos ambientais indicam que o caminho hermenêutico permite entender que o Novo Código Florestal não anistiou os infratores, mas impôs condições novas para conferir efetividade plena aos ditames do artigo 225 da CF/88.
\end{abstract}

Palavras-chave: Código Florestal; Lei 12.651/12; Danos Ambientais; Irretroatividade da Lei. 
NON-RETROACTIVITY OF THE NEW FORESTRY CODE AND THE SUPREME COURT JURISPRUDENCE

\section{ABSTRACT}

This paper points out some reflections about the constitutionality of the New Forestry Code, as viewed in the Brazilian Supreme Court judgement, performed in February of 2018. It is discussed the possibility of amnesty to environmental polluter agents, due to a misinterpretation of that legal diploma. Thus, starting from the analysis of the discourse of the votes of the Supreme Court Ministers, it is intended to subsidize a conciliatory thesis to allow the understanding that the prohibition of retroactivity in environmental matters does not limit the legislator. In the same way, the balance between the most beneficial retroactivity of the law and the need to repair environmental damage indicates that the hermeneutical path allows us to understand that the New Forest Code did not ameliorate the offenders but imposed new conditions to give full effect to the dictates of Article 225 of $\mathrm{CF} / 88$.

Keywords: Forest Code; Law 12,651 / 12; Environmental Damage; Nonretroactivity of the Law. 


\section{INTRODUÇÃO}

Para o imaginário comum, pode parecer que o julgamento pelo Supremo Tribunal Federal (STF) em fevereiro de 2018, quando conheceu uma série de argumentos a respeito da inconstitucionalidade de muitos dispositivos do atual Código Florestal (Lei Federal n. 12.651/12), estaria a autorizar uma hipótese permissiva de retroatividade para o fim de beneficiar o infrator degradador, em eventual retrocesso à preservação do meio ambiente no Brasil ${ }^{1}$.

Esse esforço de imaginação decorre da polêmica que se estabeleceu a partir de uma interpretação deliberada por aquela Suprema Corte quando, no ponto que interessa e por apertada maioria, entendeu por constitucional o permissivo contido no art. 60 da lei, que dispõe sobre a proteção da vegetação nativa, estabelecendo, por sua vez, a suspensão da punibilidade no caso de crimes ambientais, no curso do cumprimento do termo de compromisso para regularização de imóvel ou posse rural assinado perante o Órgão Ambiental competente, após adesão ao Programa de Regularização Ambiental (PRA) disciplinado no art. 59 do mesmo diploma legal.

Nesse sentido, reconheceu a constitucionalidade daquilo que se convencionou divulgar como "anistia ambiental" introduzida pelo Novo Código Florestal, tendo como beneficiários agentes que cometeram delitos contra a natureza antes de 22 de julho de 2008, alimentando uma sensação de impunidade e gerando um sentimento de que o "crime compensa", diante da inércia do poder público.

Sem dúvida alguma, acerca dessa abordagem (dentre todos os 58 artigos questionados no âmbito do STF, num universo de 84 artigos constantes do Novo Código), é que se travou uma das mais acirradas discussões jurídicas, para se definir, na interpretação daquele regime legal, se houve ou não o estabelecimento de mais uma espécie de "perdão legislativo" em nosso ordenamento jurídico.

A respeito dos fundamentos do mesmo julgamento e sobre o mérito dessa discussão, retomaremos o tema com mais vagar na última parte deste escrito, mostrando que permanece o entendimento de que o Novo Código Ambiental não pode retroagir de forma alguma para prejudicar o meio ambiente, ainda que o dito "perdão" legislativo tenha sido admitido

1 Julgamento concluído na sua quinta seção, em 28 de fevereiro de 2018, tendo como Relator o Min. Luiz Fux, para a ADI n. 4903, quando por conexão também se decidiram pleitos de inconstitucionalidade arguidos nas ADI's n. 4901, 4902 e 4937, bem como na ADC n. 042. 
pela nossa Suprema Corte.

Ocorre que, na seara ambiental, por estarmos tratando de um interesse difuso, tendo por objeto bens inalienáveis (que todos podem usar, mas, sem deles dispor), converge o nosso sistema jurídico para a sua integral proteção, não se limitando apenas a essa questão de ocorrência ou não de uma suposta "anistia", mas se ponderando o caso, por via de convergência, com outras categorias jurídicas de igual importância de precedência e alinhamento com a melhor tutela do meio ambiente.

Assim é que, neste rápido tempo de reflexão, vamos procurar demonstrar que o fenômeno da retroatividade do Novo Código Florestal, para dar guarida a danos ao meio ambiente ou mesmo eximir de responsabilidades os seus infratores, em todas as suas esferas públicas de proteção (penal, civil e administrativa), não seria, por ora, possível e nem defensável, mesmo depois da noticiada decisão colegiada proferida em sede de controle concentrado de constitucionalidade.

Com efeito, e não dito pelo STF naquele julgamento, sustentam ainda sobredita tese e por arrasto de argumentação outros motivos jurídicos que devem necessariamente ser considerados nessa discussão de não permissibilidade e que restaram já estabelecidos por nossos tribunais superiores noutras ocasiões, principalmente aqueles que dizem respeito à imprescritibilidade do dano ambiental, assim como o parâmetro que fixa como limite axiológico para tal hipótese o vetor da proibição de retrocesso, como se verá no decorrer deste texto.

\section{IMPRESCRITIBILIDADE DO DANO AMBIENTAL}

Pode-se afirmar, de maneira sucinta e sem adentrar no mérito doutrinário da prescrição do dano ambiental, que, no Superior Tribunal de Justiça (STJ), tal questão enveredou para uma pacificação jurisprudencial, a estabelecer certa segurança jurídica e social no plano da defesa do meio ambiente.

No entanto, essa imprescritibilidade resolvida no seio daquela Corte Superior se limita à responsabilização civil do agente causador do dano ao meio ambiente, forte no imperativo categórico do poluidor-pagador e na teoria da responsabilidade objetiva, independentemente da culpa do sujeito, tendo, ainda, em mente, que estamos a tratar de um direito difuso e reservado para as futuras gerações, na linha argumentativa do direito intergeracional. 
A força da ideia existe, na medida em que o dano ambiental, além de ferir o bem jurídico que lhe está próximo, também atinge a todos indistintamente, espraiando-se pela humanidade, alcançando a todos pela irreversibilidade do mal causado às gerações futuras. Por isso é que o pedido de reparação de danos ambientais, dentro da logicidade hermenêutica, tem que estar protegido pelo manto da imprescritibilidade, por se tratar de direito inerente à vida, fundamental e essencial à afirmação dos povos, independentemente de não estar expresso em texto legal.

Em matéria de prescrição, segundo o STJ, cumpre primeiro distinguir qual o bem jurídico tutelado; ou seja, se eminentemente privado, seguem-se os prazos normais das ações indenizatórias; entretanto, se o bem jurídico é indisponível e fundamental à vida humana, como acontece com o meio ambiente ecologicamente equilibrado e antecedendo a todos os demais direitos, considera-se imprescritível o seu desejo de reparação. Desse modo, o dano ambiental inclui-se dentre os direitos irrenunciáveis e, nessa categoria, estaria entre aqueles poucos acobertados pelo manto da imprescritibilidade a uma ação que vise à sua eficiente reparação ${ }^{2}$.

Sem embargo do posicionamento consolidado naquela Corte Cidadã, não desconhecemos que no STF o enfrentamento da mesma matéria acha-se ainda em aberto, mormente com o advento do Texto Constitucional emancipatório de 1988 e somos sabedores da inclinação atual para uma maior flexibilização por parte da nossa Suprema Corte, como acontecido no julgamento do Novo Código Florestal, cuja análise do seu veredicto restará novamente considerada ao final deste artigo.

Assim, em sede ambiental, o aspecto temporal ganha maior importância na medida em que a potencialidade das condutas lesivas aumenta com a submissão do patrimônio natural, de forma ampla, aos agentes degradadores, ainda que os impactos sejam antigos e a resiliência do meio tenda a um novo equilíbrio dinâmico. Como forma de melhor compreender e enfrentar os efeitos desses impactos, é que, no bojo da esfera penal, tende-se a qualificar alguns delitos desse jaez como permanentes ou continuados, dificultando também, nesse âmbito de responsabilização, a ocorrência da prescrição da pretensão punitiva.

Particularmente no STF, a discussão para se classificar (no caso concreto) crime ambiental como permanente ou instantâneo remanesce sem

2 Os argumentos alhures têm sido repristinados em diversos julgados do STJ. Por uma questão de síntese, recomenda-se consultar os termos decisórios do REsp. n. 1120117/AC, Rel. Ministra ELIANA CALMON, SEGUNDA TURMA, julgado em 10/11/2009, DJe 19/11/2009. 
uma sólida definição, há mais de quinze anos, mas com forte tendência para um posicionamento que melhor atenda à proteção da natureza, porquanto, se permanente, o lapso temporal somente começa a fluir quando cessar a permanência. Como o prazo prescricional não encontra o seu termo inicial de ocorrência e se protrai no tempo, o tratamento do fato passa a ser de um crime continuado, em franca benevolência com o meio ambiente e colocando o seu infrator numa posição de constante pendência com a justiça criminal ${ }^{3}$.

Mas, tudo isso para registrar neste tópico que, nas hipóteses de responsabilização cível, advoga a favor do ambiente o tempo sem limites de fluência, enquanto na esfera penal o prazo prescricional (a depender do dano e complexidade do caso concreto) poderá ainda permanecer em aberto, se protraindo no tempo até que cesse a sua permanência. $\mathrm{O}$ mesmo raciocínio aplicar-se-ia ao caso de uma pretensa anistia, pois é pacífico na literatura (eg. JESUS, 2014) que, mesmo anistiada determinada conduta, o dever de reparação do dano na esfera cível persistiria.

Pelo exame dos precedentes dessas duas cortes, tanto no STJ quanto no STF, o movimento jurisprudencial se compadece com as causas ambientais, estando esses tribunais cada vez mais instrumentalizados com ferramentas processuais que não beneficiam ou, no mínimo, dificultam a vida dos agentes danosos à natureza no Brasil.

E tais posicionamentos independem das recentes lições hauridas no julgamento sobre os dispositivos do Novo Código Florestal, uma vez que anteriores àquela decisão e, talvez, tenham até informado o caráter protetivo de muitos Ministros que se inquinaram pela sua incondicional defesa, no momento do controle concentrado de constitucionalidade.

Por isso, a tese de retroagir a recente legislação aprovada, depois de passada pelo crivo do STF para beneficiar o causador de dano ao meio ambiente, já nasce fadada ao insucesso, tendo que primeiro transpor os rígidos parâmetros da fluidez do tempo, em incessante transcurso para efeito de responsabilização, como antes destacado.

$\mathrm{E}$, se não bastasse isso, dificulta ainda mais uma possível interpretação retroativa in bonum partem, a favor do degradador, quando se envereda para outro contraponto de vedação, qual seja, o óbice do primado da proibição do retrocesso em sede ambiental, como será explicado e a seguir.

3 A respeito desse assunto, consulte-se notícia de 02 de dezembro de 2003, na qual a "Primeira Turma do Supremo discute proteção ambiental e crime permanente", disponível no seguinte sítio eletrônico: http://www.stf.jus.br/portal/geral/. E mais recentemente, confiram-se os fundamentos de arquivamento constantes do Inquérito n. 3.742/DF, rel Min. Luiz Fux, j. 18.10.2016. 


\section{A PROIBIÇÃO DO RETROCESSO}

Pelo que se ouviu na discussão no STF acerca das arguições de inconstitucionalidade do Novo Código Florestal, os embates ideológicos que serviram de base para ratificar os dispositivos questionados reuniram, de um lado, ministros desenvolvimentistas e com uma preocupação econômica; e, de outro,mais conservadoristas da natureza, muitos imbricando para extrair do princípio da proibição do retrocesso um sentido que melhor agasalhasse suas pretensões argumentativas.

Significa dizer que, num eventual acordo entre aquelas correntes de pensamento, necessariamente haverão de intermediar não apenas um significado que muito se aproxime do consenso, mas, também, a real extensão do que se entenda pela vedação do retrocesso em matéria ambiental, algo inédito enfrentado dentro do próprio STF e que, por certo, muito alimentará o debate acadêmico.

Até pouco tempo não manejado por razões ambientais e de origem alemã, a proibição de retrocesso se formou em torno das questões sociais na Alemanha que, nos idos de 1970, enfrentava enorme crise econômica com o real agigantamento do Estado Social, cujo aparelhamento não dava conta das demandas dessa qualidade que, apesar de não previstas constitucionalmente na Lei Fundamental de Bonn, eram defendidas como de caráter irreversível por sua natureza de direitos humanos (NOVAIS, 2010).

Muito vago e de precisão indefinida ainda hoje, esse princípio se estenderia para toda e qualquer forma de proteção de direitos fundamentais, em face de medidas entabuladas pelo poder público (com destaque para o legislador e o administrador), que tenham por escopo a supressão ou mesmo restrição de direitos fundamentais, sejam eles sociais ou de outra natureza humana, na linha de um direito constitucional de resistência e manutenção das conquistas estabelecidas (SARLET, 2009).

E no Brasil, mais precisamente no STF, a primeira vez que a vedação ao retrocesso apareceu como instrumento de proteção aos direitos fundamentais foi no julgamento da ADI n. 3.105, ocorrido no dia 18 de agosto de 2004, tendo como Relator o Ministro Cezar Peluso, oportunidade em que, por maioria de votos, se considerou constitucional a Emenda 41, autorizando instituir contribuição previdenciária sobre os proventos dos servidores inativos. Coube ao Ministro Celso de Mello analisar o âmbito de incidência desse princípio, no momento em que votou 
pela inconstitucionalidade daquela tributação, registrando que a conquista da garantia de não mais contribuir para o regime previdenciário com o ato de aposentação não poderia ser suprimida, para obrigar os aposentados e pensionistas a continuarem como contribuintes do sistema, sob pena de retrocesso ilegítimo desse direito.

Após lembrança durante aquele controle concentrado de constitucionalidade, outros julgamentos seguiram dentro do STF, dando relevância e destaque para a proibição de retrocesso ${ }^{4}$, até que, em meados de 2012, se consolida essa vedação teórica como um novo instrumento adaptado e de resistência em favor da natureza ${ }^{5}$, culminando com sua abordagem feita de forma inédita por esse viés pela Excelsa Corte, por ocasião dos debates travados sobre a constitucionalidade do Novo Código Florestal, momento em que se debruçaram os Ministros para verificar a possibilidade de flexibilização, assim como de diminuição do campo de proteção dos muitos bens ambientais, em relação ao regime legal anterior, podendo nós já, a partir dessas primeiras considerações, traçar alguns encaminhamentos de aplicação daquele princípio dentro do STF, mesmo que não manifestado expressamente ou por completo o pensamento de todos os julgadores sobre esse peculiar modo de encarar seu deslocamento para a arena do meio ambiente.

Abrindo divergência durante o julgamento destacado, não necessariamente na ordem dos votos, registra-se o comportamento do Ministro Gilmar Ferreira Mendes que, fiel aos seus ensinamentos doutrinários escritos há quase uma década, advogou a tese de que se deve procurar compreender o princípio da vedação do retrocesso como modalidade do princípio da proporcionalidade, não devendo ele se constituir, em termos absolutos, um óbice intransponível ao múnus do legislador ordinário, na produção das leis do nosso país, ou na edição de emendas constitucionais que, eventualmente, venham a limitar ou mesmo suprimir direitos sociais. No entanto, para que tais atos normativos tenham

4 Ilustrativamente, seguem precedentes do STF em que o princípio da proibição do retrocesso teve relevância: ARE no 639.337-AgR (Rel. Min. Celso de Mello, j. 23-8-2011, Segunda Turma, DJE de 15-9-2011 e o RE no 398.041 (Rel. Min. Joaquim Barbosa, julgamento em 30-11-2006, Plenário, DJE de 19-12-2008).

5 Ingo Wolfgang Sarlet revela que teve a oportunidade de participar, juntamente com outros renomados especialistas no direito ambiental, tais como Michel Prieur, Herman Beniamin, Caros Alberto Molinaro, Patryck de Araújo Ayala, Tiago Fensterseifer e Walter Claudius Rothenburg, do Colóquio Internacional sobre o Princípio da Proibição de Retrocesso Ambiental, realizado pela Comissão de Meio Ambiente, Defesa do Consumidor e Fiscalização e Controle (CMA) do Senado Federal, sob a presidência do então Senador Rodrigo Rollemberg, em 29 de março de 2012, cujas palestras foram reunidas sob o formato do livro O princípio da proibição de retrocesso ambiental. Brasília: Senado Federal/CMA, 2012 (SARLET, 2016). 
sua validade constitucional certificada, será necessário que resistam ao teste tríplice da proporcionalidade (adequação, necessidade e proporcionalidade em sentido estrito, conforme Mendes, 2015).

No decorrer dos debates, Gilmar Mendes obtemperou que o STF corre o risco de passar por cima da análise do Congresso Nacional, em nome da proibição do retrocesso, isso depois da aprovação de uma lei "extremamente técnica" e resultante de mais de duzentas audiências públicas, contando com a participação de todos os setores representativos da sociedade relacionados à matéria. Tudo isso era realmente necessário porque os parâmetros do código anterior de 1965, na sua visão, já não eram cumpridos e, diante dessa constatação, criaram uma nova legislação mais eficaz e conciliatória com os princípios da ordem econômica, num autêntico processo de convergência para restaurar um mínimo de normatividade no campo ambiental (POMPEU, 2018).

Essa controvérsia no modo de encarar tal possibilidade de retrocesso se estendeu pelos outros votos, mesmo que não necessariamente repercutindo no encaminhamento do mérito da questão, como aconteceu com a manifestação do Ministro Alexandre de Morais que, na esteira da constitucionalidade defendida pelo relator, disse não considerar possível analisar as normas recentes trazidas pelo Novo Código Florestal, com base somente no regime anterior, uma vez que o cenário atual da agricultura, assim como demais métodos de produção e recomposição ambiental, em muito evoluíram tecnologicamente nos dias de hoje, razão pela qual não compreende de forma estanque a ideia da vedação do retrocesso (POMPEU, 2018).

Também o Ministro Celso de Mello, primeiro na Corte a prestigiar esse mesmo primado há quase quinze anos, houve por bem agora, novamente, citar a proibição do retrocesso como defesa do meio ambiente, não significando dizer que a atividade econômica e o "dinamismo da atividade do Estado" devam ser impedidos, mas, entendendo que esse princípio deve servir como referência tanto para o Legislativo quanto para o Executivo, na condução das políticas públicas ambientais, tudo por deferência judicial ao planejamento estruturado pelos demais poderes da República. No entanto, e quando houver dúvida se determinada conduta prejudicará o meio ambiente e os cidadãos em geral, deve sempre prevalecer o princípio in dúbio pro natura, segundo termos colhidos no seu voto, já disponibilizado por meio eletrônico.

Citando expressamente o mesmo princípio como uma das 
suas razões de decidir, Luís Roberto Barroso detalhou que a proteção ao meio ambiente haverá de ser ponderada conjugando-se exigências do desenvolvimento econômico, vedação ao retrocesso social e limitações à intervenção da justiça na atividade do legislador, restrita apenas a casos de "manifesta falta de razoabilidade e desproporcionalidade da medida". Para Carmem Lúcia, no campo limitado da extensão do princípio que se debate, não seria compatível com a Constituição Federal, em nome de uma "flexibilização" da legislação ambiental, aniquilar-se direito que tenha sido conquistado, ainda mais em tema de importância enorme como esse, a cuidar do tipo de comprometimento de direitos, que atinge não somente a atualidade, mas gerações vindouras da humanidade (POMPEU, 2018).

Com efeito, é possível perceber que a questão se acha em aberto na Suprema Corte, não havendo discernimento da posição pontual de muitos ministros acerca da matéria, mormente no entremeio de um tenso processo de discussão teórica e ideológica.

Por ser muito recente e não disponibilizados os votos da maioria dos julgadores, bem como, considerando-se neste aspecto que nem sempre esse voto escrito representa a fidelidade dos debates orais por nós assistidos, certamente teremos novos e futuros desdobramentos da extensão daquele princípio em sede ambiental, a dificultar ou mesmo lançar no campo da incerteza um eventual esforço de retroatividade do Novo Código Florestal, para beneficiar os causadores de danos ao meio ambiente.

Até porque a retroação para tal fim não foi autorizada pelo STF, no referido controle de constitucionalidade, máxime quando aquela Corte conheceu da suposta "anistia" dos crimes ambientais e, por apertada maioria, referendou o "perdão" legislativo sob outra forma de enxergar a questão e com vantagens maiores de recuperação para o meio ambiente, como segue detalhado no próximo item.

Assim, por ora, resta legítimo como vértice norteador para os demais tribunais do nosso país o entendimento mais maduro e firmado há bem mais tempo pelo STJ, para quem

o novo Código Florestal não pode retroagir para atingir o ato jurídico perfeito, direitos ambientais adquiridos e a coisa julgada, tampouco para reduzir de tal modo e sem as necessárias compensações ambientais o patamar de proteção de ecossistemas frágeis ou espécies ameaçadas de extinção, a ponto de transgredir o limite constitucional intocável e intransponível da 'incumbência' do Estado de garantir a preservação e 
Dessa feita, e até que o STF retome a discussão por força do engate constitucional antes anotado, entende-se que prevalece a maior extensão conferida pela Corte da Cidadania, quando se trata de proteção da natureza e vedação do retrocesso, a fim de beneficiar o agente causador do dano ambiental.

\section{A CONSTITUCIONALIDADE DA SUPOSTA "ANISTIA" POR PARTE DO STF}

Decorre sintomaticamente da aplicação ou não do princípio da proibição do retrocesso e seus concretos efeitos, por exemplo, a possibilidade de se "anistiar" os agentes que cometerem crimes contra o meio ambiente antes de 22 de julho de 2008, a teor do art. 60 do Novo Código Florestal, dentro de uma lógica noticiada de que isso se configuraria num benefício concedido pela recente legislação, visando a proveito direto e exclusivo dos agentes devastadores da natureza, possibilitando aos mesmos atores oportunidade de se eximirem das suas criminosas responsabilidades.

Entretanto, não foi essa a leitura dada pela apertada maioria que se construiu dentro do STF, a partir dos enunciados normativos dos arts. 59 e 60 daquele código, impressionados que ficaram pelo fato de que o aludido "perdão" legislativo veio atrelado a uma série de condicionantes que devem ser impostas e ajustadas com a peculiaridade dos fatos, mediante análise final do caso concreto e na contramão daquilo que defendeu o Ministro Relator, no seu voto inaugural. Para Luiz Fux, a lei em exame conferiu verdadeira "anistia condicional" aos infratores, em total desconformidade com o art. 225, parágrafo $3^{\circ}$, da $\mathrm{CF} / 88$, que estabelece para eles sanções penais e administrativas, independentemente da obrigação de reparar os danos causados ${ }^{6}$.

Marco Aurélio acompanhou o entendimento e disse que nada justifica uma "anistia" concedida aos produtores rurais em relação aos danos ocorridos antes de julho de 2008, não se podendo prestigiar proprietários infratores em detrimento daqueles que arcaram com o ônus econômico de observar a lei, alimentando, doravante, a expectativa de futuras isenções da mesma significância (POMPEU, 2018). Mas, no desempate dessa controvérsia, Celso de Mello sustentou que referido "perdão" não se

6 Segundo notícia vinculada no sítio oficial e eletrônico do STF sob o título: "Relator profere voto no julgamento sobre o Novo Código Florestal”, às 19:55 hrs. do dia 08/nov/17. 
reveste de conteúdo arbitrário e nem compromete a tutela constitucional do meio ambiente, pois esta foi deferida no contexto de uma "clemência do Estado" que se estende a todos os demais crimes comuns e não se limita apenas à esfera dos delitos políticos?

Do que se pode perceber, e a partir da visão interpretativa dessa apertada maioria, prestigiou-se, no limiar do ponderável, e dentro de uma razoabilidade negociada, todo o esforço empreendido pelo legislador ordinário, na sua tentativa de aproximar interesse econômico de um lado e preservação da natureza do outro, restando muito claro que, tanto empreendedor quanto defensores do meio ambiente acabaram cedendo espaços até o limite da preservação do núcleo essencial de cada uma das normas de interesse. Tal ideia, já presente na obra de Derani (2001), nada mais representa que o exercício de compatibilização de direitos fundamentais constitucionais em aparente tensão. A referida autora já acenava para a integração daqueles direitos, alçando o direito ao meio ambiente ecologicamente equilibrado a balizador do desenvolvimento econômico.

Não dito exatamente nesses termos naquele julgamento e por obra da compreensão generalizada do que dele se pode extrair, imaginase que a maioria procurou, antes, desvendar o conteúdo desse núcleo essencial para, logo em seguida, respeitá-lo, mantendo-o íntegro no modo otimamente realizável que conseguiram vislumbrar, numa perspectiva teórica que vem se consolidando como garantia de conteúdo essencial dos direitos fundamentais no Brasil ${ }^{8}$.

Significa dizer que não necessariamente se esteja de acordo com o resultado final desse encaminhamento, mas', na balança do sopesamento permitido e com espeque nessa última teoria, a maior parte dos julgadores decidiu tergiversar a natureza jurídica do que se entende por "anistia" e - mesmo quando alguns a reconheciam como tal - era vista como uma hipótese aceitável de prestígio ao núcleo essencial das normas em consideração, porquanto quem, ao cabo, estaria ganhando com esse exercício de busca para a melhor interpretação, seria o próprio meio ambiente, como se tentará agora reforçar.

A premissa dessa constatação escorre da resposta às seguintes

\footnotetext{
7 Fundamentos resumidos e colhidos do voto do Ministro Celso de Mello, já disponibilizado para consulta no sítio eletrônico do STF, dentro das ADI's que suscitaram a matéria.

8 A respeito dessa abordagem, sugere-se consultar trabalho de Sandro Nahmias Melo, publicado sob o título "A garantia do conteúdo essencial dos direitos fundamentais". Revista de Direito Constitucional e Internacional. São Paulo, ano 11, abr./jun. 2003, n. 43, p. 82-97.
} 
indagações: de que adiantaria insistir na punição do infrator, já que a natureza permaneceria agredida e devastada? E como ficaria o dever de restauração fincado como independente das sanções penais e administrativas, segundo preceito do art. 225 , par. $3^{\circ}, \mathrm{CF} / 88$, e defendido no voto do relator?

Informados por um realismo jurídico nacional, outros declarando expressamente a ineficácia da antiga legislação na defesa do meio ambiente, enveredou a maioria do STF pela crença de que a reparação preconizada por instrumentos do antigo código dificilmente se realizaria, quer porque uma vez condenado o infrator não teria mais estímulo voluntário para isso, quer porque o atual desaparelhamento do Estado na condução dessa recomposição não a tornaria eficaz.

Com a adesão do causador do dano ao Programa de Regularização Ambiental (PRA), firmando, por consequência e voluntariamente, o termo de compromisso com suas exigências restaurativas, desde que favoráveis à manutenção dos recursos naturais e na linha garantidora do seu núcleo essencial, estaria valendo a pena anistiar esse infrator compromissário em homenagem ao maior benefício da natureza. No final das contas, e como se deliberou de modo apertado dentro do STF, esse resultado alcançado seria muito mais pró-afirmativo à manutenção da higidez ambiental.

Quanto à outra parte infratora, pode-se até entender que a ela foi dada uma segunda oportunidade para se redimir no que toca ao seu ato criminoso, mas, por contrapartida, teve que agora confessar o seu delito, assumir uma série de novas imposições administrativas e, principalmente, restaurar o ambiente danificado como condição para recebimento do "perdão". Depois de tudo isso feito, parece razoável e bem defensável que quem muito mais ganhou do que perdeu foi a destinatária natureza, já que, uma vez recomposta, passará a ser cuidada e fiscalizada também pelo seu antigo "malfeitor", numa racionalidade lógica de que mais um "soldado" restará engajado na guerra contra a sua devastação.

Nessas circunstâncias é que há quem defenda que os causadores do dano não estariam sendo indevidamente beneficiados, pois, doravante, teriam que procurar sponte propria o poder público, apontar suas transgressões e assumir prazos a fim de cumprir atividades restaurativas, movimentos aos quais não eram anteriormente obrigados, estando à mercê deles na época uma pleura de mecanismos processuais a garantir o devido processo legal, contraditório e com amplitude de defesa no âmbito justamente da complexidade a que se resumem as demandas ambientais. Essa demora na final resolução do processo poderia conduzir, quem sabe 
e no campo das eventualidades, a uma possível prescrição da pretensão punitiva por parte do Estado brasileiro.

Nesse sentido, destaque-se que o Supremo Tribunal Federal reconheceu a repercussão geral de matéria relativa à prescrição de pedido de reparação de dano ambiental. Consoante matéria publicada recentemente em seu sítio eletrônico, o tema é objeto do Recurso Extraordinário (RE) 654833, que versa sobre dano causado por madeireiros na explotação irregular de terras indígenas no Acre, nos anos 1980, em relação ao qual se pretende afastar a tese da imprescritibilidade. Ressalte-se que o voto do Ministro Alexandre de Moraes pelo reconhecimento da repercussão geral foi acompanhado pelos demais ministros; entretanto, o mérito do recurso será submetido ao Plenário na Corte, ainda sem data prevista para julgamento (STF, 2018).

Longe da discussão se ocorreu ou não "anistia" por parte do Novo Código Florestal e referendado pelo STF, importa daqui para a frente aceitar aquela decisão e compreender que veio ela para dar eficácia restaurativa ao meio ambiente e não circunstanciada ao benefício exclusivo do degradador, também não se permitindo, de forma alguma, que volte ele a transgredir, em respeito ao princípio da vedação do retrocesso por parte dos atos de Estado que, na sua interpretação estendida e achada dentro da nossa Suprema Corte, deu ainda guarida ao comentado "perdão", por ser de melhor proveito na defesa dos nossos recursos naturais.

\section{CONCLUSÃO}

Como demonstrado, todo o funcionamento do sistema e sua interpretação operam a favor do meio ambiente, ora procurando dar efetivação tanto na sua proteção quanto na restauração dos espaços irregularmente degradados, ora contornando situações que, num primeiro momento, poderiam beneficiar o causador do dano, com leitura mais favorável, numa linha argumentativa em que sempre deve prevalecer o interesse da natureza, nos exatos padrões técnicos da sua sustentabilidade.

Mesmo nos casos em que se legisla aparentemente para beneficiar esses causadores do dano ambiental, como se viu anteriormente, o vetor garantidor do núcleo essencial da norma haverá de ser descortinado para se apontar, no percurso desse processo de inteligência, os reais, concretos e efetivos proveitos ambientais, mediante razoáveis e convincentes argumentos de que deve prevalecer o esforço da preservação e/ou 
recuperação da natureza, ainda que ao preço de voltarmos a negociar com seus anteriores e identificados agentes devastadores.

Em síntese, não seria racional interpretar o Novo Código Florestal como norma permissiva e hábil a retroagir tão somente em benefício desses infratores, se a própria Constituição Federal assegura ao direito ambiental o status de fundamental para presentes e futuras gerações, afigurandose como importante conquista socioambiental, hodiernamente protegida pelo manto da vedação ao retrocesso em sua maior amplitude possível de proteção.

Como ficou registrado, não se pode subverter o funcionamento de um ordenamento jurídico voltado para a garantia do meio ambiente saudável, ainda que ponderado pela necessária atividade econômica, quando outros e poderosos instrumentos de tutela pro natura convergem para a sustentabilidade da vida no planeta, intimamente ligada à manutenção desses mesmos recursos naturais.

Pelo exposto, não convence a tese de uma eventual retroação do Novo Código Florestal, a fim de apenas beneficiar o agente causador do dano ambiental, podendo isso até acontecer por via reflexa e no máximo do ponderável, em vista de um salutar processo de otimização e desde que, ao final, melhor vantagem se atribua para recuperação da natureza.

\section{REFERÊNCIAS}

DERANI, Cristiane. Direito Ambiental Econômico. São Paulo: Max Limonad, 2001.

JESUS, Damásio Evangelista. Direito Penal: Parte Geral. 34 ed. São Paulo: Saraiva, 2014.

MACHADO, Paulo A. Leme. Direito ambiental brasileiro. 24 ed. São Paulo: Malheiros, 2016.

MELO, Sandro Nahmias. A garantia do conteúdo essencial dos direitos fundamentais. Revista de Direito Constitucional e Internacional. São Paulo, ano 11, abr./jun. 2003, n. 43, p. 82-97.

MENDES, Gilmar Ferreira; BRANCO, Paulo Gustavo Gonet. Curso de direito constitucional. $10^{\mathrm{a}}$ ed. São Paulo: Saraiva, 2015.

NOVAIS, Jorge Reis. Direitos sociais. Coimbra: Coimbra, 2010. 
POMPEU, Ana. Limite de proibição ao retrocesso ambiental é ponto controverso no STF. Consultor Jurídico. Diversidade de entendimentos. São Paulo, 22/fev/2018.

POMPEU, Ana. Para Cármen Lúcia, trechos do Código Florestal "aniquilaram" direitos ambientais. Consultor Jurídico. Gerações futuras. São Paulo, 21/fev/2018.

SARLET, Ingo Wolfgang. A assim designada proibição de retrocesso social e a construção de um direito constitucional comum latinoamericano. Revista Brasileira de Estudos Constitucionais - RBEC. Belo Horizonte, ano 3, n. 11, jul./set. 2009.

SARLET, Ingo Wolfgang. A proibição de retrocesso na proteção e promoção de um meio ambiente saudável. Consultor Jurídico. Direitos Fundamentais. São Paulo, 25/mar/2016.

SUPERIOR TRIBUNAL DE JUSTIÇA. Recurso Especial n. 1120117/AC. Relatora: Ministra: Eliana Calmon - Recorrente: Orleir M. Cameli e outro - Recorrido: Ministério Público Federal e outro - Brasília, 26, ago. 2010.

SUPERIOR TRIBUNAL DE JUSTIÇA. Recurso Especial n. 327687/SP AgReg. Relator: Ministro: Humberto Martins - Recorrente: Maria Regina A.V. de Andrade e outros - Recorrido: Ministério Público do Estado de São Paulo - Brasília, 15, ago. 2013.

SUPREMO TRIBUNAL FEDERAL. Ação Declaratória de Constitucionalidade n. 042. Relator: Ministro: Luiz Fux - Autor: Partido Progressista (PP) - Ré: União Federal - Assunto: Inconstitucionalidades da Lei federal n. n. 12.651/12 - Brasília, 28, fev. 2018.

SUPREMO TRIBUNAL FEDERAL. Ação Direita de Inconstitucionalidade n. 4901. Relator: Ministro: Luiz Fux - Autor: Procurador Geral da República - Ré: União Federal - Assunto: Inconstitucionalidades da Lei federal n. n. 12.651/12 - Brasília, 28, fev. 2018.

SUPREMO TRIBUNAL FEDERAL. Ação Direita de Inconstitucionalidade n. 4902. Relator: Ministro: Luiz Fux - Autor: Procurador Geral da República - Ré: União Federal - Assunto: Inconstitucionalidades da Lei federal n. n. 12.651/12 - Brasília, 28, fev. 2018.

SUPREMO TRIBUNAL FEDERAL. Ação Direita de Inconstitucionalidade n. 4903. Relator: Ministro: Luiz Fux - Autor: Procurador Geral da 
República - Ré: União Federal - Assunto: Inconstitucionalidades da Lei federal n. n. 12.651/12 - Brasília, 28, fev. 2018.

SUPREMO TRIBUNAL FEDERAL. Ação Direita de Inconstitucionalidade n. 4937. Relator: Ministro: Luiz Fux - Autor: Partido Socialismo e Liberdade (PSOL) - Ré: União Federal - Assunto: Inconstitucionalidades da Lei federal n. n. 12.651/12 - Brasília, 28, fev. 2018.

SUPREMO TRIBUNAL FEDERAL. Inquérito Policial n. 3742/DF Relator: Ministro: Luiz Fux - Autor: Ministério Público Federal - Indiciado: Ivo Narciso Cassol - Assunto: Crimes contra o meio ambiente - Brasília, 20, out. 2016.

SUPREMO TRIBUNAL FEDERAL. Prescrição de ressarcimento de dano ambiental é tema de repercussão geral. Disponível em: http://www. stf.jus.br/portal/cms/verNoticiaDetalhe.asp?idConteudo=380229\&utm source $=$ dlvr.it\&utm_medium=facebook. Acessado em 04/07/2018.

SUPREMO TRIBUNAL FEDERAL. Recurso Extraordinário n. 398041. Relator: Ministro: Joaquim Barbosa - Recorrente: Ministério Público Federal - Recorrido: Sílvio Caetano de Almeida - Brasília, 30, nov. 2006.

SUPREMO TRIBUNAL FEDERAL. Recurso Extraordinário n. 639337 - AgrReg. Relator: Ministro: Celso de Mello - Recorrente: Município de São Paulo - Recorrido: Ministério Público do Estado de São Paulo Brasília, 01, set. 2011.

\section{Como citar este artigo (ABNT):}

SILVEIRA, Edson Damas da; CAMARGO, Serguei Aily Franco de. A IRRETROATIVIDADE DO NOVO CÓDIGO FLORESTAL E A JURISPRUDÊNCIA DO SUPREMO TRIBUNAL FEDERAL. Veredas do Direito, Belo Horizonte, v. 15, n. 33, p. 191-207, set./dez. 2018. Disponível em: <http://www.domhelder.edu.br/revista/index.php/veredas/ article/view/1309>. Acesso em: dia mês. ano.

Artigo recebido em: 11/07/2018

Artigo aceito em: 20/11/2018 